University of Nebraska - Lincoln

DigitalCommons@University of Nebraska - Lincoln

2008

Introduction to the ILSI Research Foundation/Risk Science

Institute reports from the expert working group on

neurodevelopmental endpoints

Julie Fitzpatrick

ILSI Research Foundation/ Risk Science Institute, jfitzpatrick@ilsi.org

Elizabeth Mendez

U.S. EPA

Isabel Walls

ILSI Research Foundation/ Risk Science Institute

Follow this and additional works at: https://digitalcommons.unl.edu/usepapapers

Fitzpatrick, Julie; Mendez, Elizabeth; and Walls, Isabel, "Introduction to the ILSI Research Foundation/Risk Science Institute reports from the expert working group on neurodevelopmental endpoints" (2008). U.S. Environmental Protection Agency Papers. 164.

https://digitalcommons.unl.edu/usepapapers/164

This Article is brought to you for free and open access by the U.S. Environmental Protection Agency at DigitalCommons@University of Nebraska - Lincoln. It has been accepted for inclusion in U.S. Environmental Protection Agency Papers by an authorized administrator of DigitalCommons@University of Nebraska - Lincoln. 
Review article

\title{
Introduction to the ILSI Research Foundation/Risk Science Institute reports from the expert working group on neurodevelopmental endpoints
}

\author{
Julie Fitzpatrick $^{\mathrm{a}, *}$, Elizabeth Mendez ${ }^{\mathrm{b}}$, Isabel Walls ${ }^{\mathrm{a}}$ \\ a ILSI Research Foundation/Risk Science Institute, Washington DC, United States \\ ${ }^{\mathrm{b}}$ US EPA, Washington DC, United States
}

\section{A R T I C L E I N F O}

\section{Article history:}

Received 20 February 2008

Received in revised form 5 March 2008

Accepted 5 March 2008

Available online 13 March 2008

\section{Keywords:}

DNT

Developmental neurotoxicity testing

Positive control studies

Variability

Statistical issues

Interpretation of DNT effects

\begin{abstract}
A B S T R A C T
In 2004 the International Life Sciences Institute (ILSI) Risk Science Institute established an expert working group to assess the lessons learned from the implementation of standardized tests for developmental neurotoxicity in experimental animals. This introduction summarizes the working group process and the four reports from the expert working group addressing: the use of positive controls, understanding variability, appropriate statistical techniques, and interpretation. The reports address the 1991 US Environmental Protection Agency standardized protocol for evaluation of developmental neurotoxicity (DNT) and the 2007 Organisation for Economic Co-operation and Development (OECD) Test Guidelines for DNT. The EPA protocol is comprised of tests for evidence of deficits in neurobehavioral function, including auditory startle habituation, motor activity, associative learning and memory, and neuropathologic examination, including simple morphometric analysis.
\end{abstract}

(c) 2008 Elsevier Inc. All rights reserved.

\section{Contents}

1. Undertaking positive control studies as part of developmental neurotoxicity testing . . . . . . . . . . . . . . . . . . 264

2. Determining normal variability in a developmental neurotoxicity test . . . . . . . . . . . . . . . . . . . . . . . . . . 264

3. Statistical issues and techniques appropriate for developmental neurotoxicity testing. . . . . . . . . . . . . . . . . . . 264

4. Identification and interpretation of developmental neurotoxicity effects . . . . . . . . . . . . . . . . . . . . . . . 264

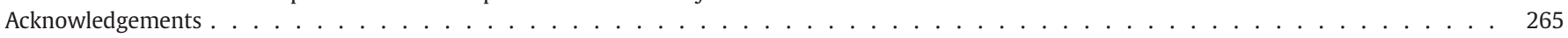

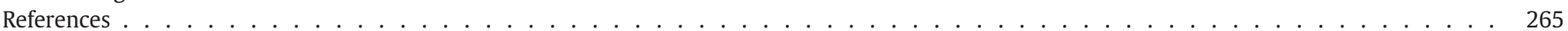

Approximately 12 million children in the United States are afflicted with a learning, developmental, or behavioral disability including neurodevelopmental disorders, such as autism, attention-deficit hyperactivity disorder, and mental retardation. The incidence of new cases of neurodevelopmental disorders appears to be increasing [1-3]. This may be due to better diagnostic techniques by pediatricians and other health care providers or may be related to changes in environmental exposures to neurodevelopmental toxins, or possibly both of these factors. Improved understanding of the neurotoxic effects of potentially toxic substances in the environment has become a public health and societal priority worldwide.

\footnotetext{
* Corresponding author. ILSI Research Foundation, Risk Science Institute, One Thomas Circle, N.W., Ninth Floor, Washington, DC 20005-5802, United States. Tel.: +1 202659 3306; fax: +1 202 659-3617.

E-mail address: jfitzpatrick@ilsi.org (J. Fitzpatrick).
}

In 2004 with the support of United States Environmental Protection Agency (US EPA), the International Life Sciences Institute (ILSI) Research Foundation/Risk Science Institute established an international expert working group on neurodevelopmental endpoints consisting of scientists possessing technical expertise from the governmental, academic, industrial, and public interest sectors. The group was charged with assessing the lessons learned from the implementation of the US EPA developmental neurotoxicity guideline. Table 1 presents the members of the expert working group. The expert working group met three times over a period of two years and developed the four reports presented in this edition of the journal. The reports evaluating the use of positive controls, addressing variability in data, use of appropriate statistical techniques, and interpretation of treatment-related effects comprise a consensus of the expertise of the work group members.

Developmental neurotoxicity (DNT) refers to any adverse effect of exposure to a toxic substance on the normal development of nervous 
Table 1

Expert working group members
Dr. Jane Adams

Dr. John M. Balbus

Dr. David Bellinger

Dr. Kevin Crofton

Dr. Penny Fenner-Crisp

Dr. J. Edward Fisher, Jr

Ms. Julie Fitzpatrick

Dr. John Foss

Dr. Les Freshwate

Dr. Scott Hancock

Dr. Ulla Hass

Dr. Keith Hazelden

Dr. R. Robert Holson

Dr. Edward D. Levin

Dr. Susan Makris

Dr. Tim Marrs

Dr. Jacques P. J. Maurissen

Dr. Elizabeth Mendez

Dr. Angelo Moretto

Dr. Virginia Moser

Dr. Sherry Parker

Dr. Whang Phang

Dr. Kathleen Raffaele

Professor David Ray

Dr. Louis Scarano

Dr. Larry Sheets

Dr. Thomas J. Sobotka

Dr. Sonya K. Sobrian

Dr. Rochelle W. Tyl
Dr. Isabel Walls
University of Massachusetts - Boston

Environmental Defense

Harvard Medical School

US Environmental Protection Agency

Consultant

US Food and Drug Administration

ILSI Research Foundation

Charles River Laboratories

BioSTAT Consultants, Inc.

Health Canada

Danish Institute of Food Safety and Toxicology

Huntingdon Life Sciences, Inc.

(current affiliation - MedImmune)

New Mexico Tech

Duke University Medical Center

US Environmental Protection Agency

Edentox Associates

US Environmental Protection Agency

Universita di Padova, Italy (current affiliation

University of Milan and Luigi Sacco Hospital,

Milan, Italy)

US Environmental Protection Agency

OrbusNeich Medical, Inc.

US Environmental Protection Agency

US Environmental Protection Agency

University of Nottingham

US Environmental Protection Agency

Bayer CropScience

US Food and Drug Administration

(current affiliation - retired)

Howard University College of Medicine

RTI International

ILSI Research Foundation
Dow Chemical Company

system structures and/or functions. Testing for developmental neurotoxicity involves functional and neuropathological assessments in experimental animal offspring during and following maternal exposure. To be most useful, animal studies must have high predictive value, both positive and negative. This means that they must include endpoints that can predict that an agent will either be neurotoxic in humans or not. Additionally, it is important that the tests be sufficiently sensitive so as to detect effects of positive agents at exposures relevant to those experience by humans.

In 1991, the US EPA issued a guideline for DNT evaluation and in 2007 the Organisation for Economic Co-operation and Development (OECD) finalized OECD Testing Guidelines for DNT [4,5]. The US EPA protocol recommends prenatal and perinatal exposure followed by pre- and post-weaning tests for evidence of deficits in neurobehavioral function, including auditory startle habituation, motor activity, associative learning and memory, and neuropathologic examination, including simple morphometric analysis.

The following is a summary of the four reports included in this issue, which when taken together, offer a review of findings from the US EPA testing paradigm for DNT testing and provide many recommendations that should enhance our ability to conduct and interpret these types of tests in the future.

\section{Undertaking positive control studies as part of developmental neurotoxicity testing}

Positive controls are "reference standards" that serve multiple purposes. Positive control data are instrumental in evaluating laboratory proficiency in detecting chemical-induced changes in measured endpoints. Positive control data are valuable in a weight-ofevidence approach to help determine the biological significance of results and to provide confidence in negative results from DNT studies. The positive control data should be derived from studies that were performed in the same laboratory within the past few years, utilizing (to the greatest extent possible) the staff and equipment that will be used in conducting the studies of interest [6]. Positive control data should demonstrate the sensitivity of the procedures used and the competence of the laboratory in the evaluation of effects in postnatal animals pre- or perinatally exposed to chemicals, in addition to establishing test norms for all critical endpoints. This report provides a practical guide for the use and interpretation of positive control studies in DNT tests, including suggestions for test substances that can be used as positive controls at the different endpoints.

\section{Determining normal variability in a developmental neurotoxicity test}

When evaluating the results of any toxicity study, it is necessary to understand the normal variability that is observed in the parameters being measured so that an evaluation can be made of whether the findings are within the normal range or outside this range. A number of intrinsic and extrinsic factors can contribute to the variability within or between subjects in DNT studies. Sources of variability include factors related to environmental conditions, personnel, experimental procedures and instrumentation. Controlling variability to the extent possible in the experiment is necessary to provide sound data for regulatory and risk assessment evaluations. This report presents a framework for investigators and regulators to use in comparing achieved versus expected levels of variability in DNT study data. Elements of the framework include: characterization of variability in the dataset; identification of appropriate datasets for comparison; evaluation of similarities and differences in variability between datasets, and examination of possible sources of the variability, including those related to test conduct and test design.

\section{Statistical issues and techniques appropriate for developmental neurotoxicity testing}

Appropriate statistical analyses of the behavioral data collected in DNT studies are imperative, including attention to within-litter correlations, gender and repeated testing as factors, and approaches specific for the different data types. This report presents an examination of the statistical approaches currently being used in DNT testing with recommendations for improving data analysis and reporting. Critical to the success of the analysis is specifying the planned statistical analyses a priori. A survey of current statistical practices from six testing laboratories revealed a range of flawed procedures. The major deficiencies that were routinely observed revolved around: Type I and II error considerations; litter allocation and analysis; analysis using sex as a factor; analysis using repeated measures; and statistical analysis assumptions.

\section{Identification and interpretation of developmental neurotoxicity effects}

The reliable detection, measurement, and interpretation of treatment-related developmental neurotoxicity (DNT) effects depends on appropriate study design and execution, using scientifically established methods, with appropriate controls to minimize confounding factors. Appropriate statistical approaches should be optimized for the specific endpoints in advance, analyzing effects across time and functional domains as far as possible. If available, biomarkers of exposure are useful to assess the bioavailability of toxicants to the dam and offspring in utero and after birth. Finally, "weight of evidence" principles are used to aid assessment of the biological significance of differences from concurrent controls. These effects should be interpreted in light of available information from historical controls, positive controls, maternal and offspring systemic toxicity, and other relevant toxicological data. This report provides a framework for the 
integration of all these types of information in the interpretation of DNT studies.

\section{Acknowledgements}

These reports were developed under the Cooperative Agreement R-83049601 between ILSI Research Foundation and the US Environmental Protection Agency Office of Pesticide Programs and Cooperative Agreement X-82916701 between ILSI Research Foundation and the US Environmental Protection Agency Office of Pollution Prevention and Toxics.

\section{References}

[1] C.A. Boyle, P. Decoufle, M. Yeargin-Allsopp, Prevalence and health impact of developmental disabilities in US children, Pediatrics 93 (1994) 399-403.
[2] L. Buxbaum, C. Boyle, M. Yeargin-Allsopp, C.C. Murphy, H.E. Roberts, Etiology of mental retardation among children ages 3-10: The metropolitan atlanta developmental disabilities surveillance program, Centers for Disease Control and Prevention, Atlanta, 2000.

[3] M. Kiely, The prevalence of mental retardation, Epidemiol. Rev. 9 (1987) 194-218.

[4] U.S. EPA, Developmental Neurotoxicity Study, Series 83-6, Addendum 10 (Neurotoxicity), Subdivision F: Hazard Evaluation: Human and Domestic Animals, U.S. EPA, Washington, DC, 1991.

[5] OECD, Organization for Economic Cooperation and Development (OECD) Guideline for the Testing of Chemicals Test No. 426: Developmental Neurotoxicity Study, 2007 http://caliban.sourceoecd.org/vl=3130160/cl=12/nw=1/rpsv/ij/oecdjournals/ $1607310 x / v 1 n 4 / s 27 / p 1$.

[6] U.S. EPA, Health Effects Guidelines OPPTS 870.6300 Developmental Neurotoxicity Study, 1998. 